\title{
APORTACIÓN AL DESARROLLO DE LA ENFERMERÍA CIENTÍFICA
}

La Enfermería de nuestro país está cambiando. Su desarrollo académico e investigador impulsa, por fin, cambios en la práctica clínica. Éste es un proceso continuo e imparable que sólo podremos analizar dentro de algunos años desde una perspectiva histórica.

El impulso para esta transformación que todas las enfermeras queremos viene desde los diversos sectores de la profesión, con proyectos que aportan creatividad, ilusión, esfuerzo, paciencia y la alegría de ver que ya podemos mirar el camino recorrido y felicitarnos.

SCELE se constituyó en el cambio de siglo, a finales de diciembre del 2000. El motivo para asociarnos fue nuestro proyecto y objetivos comunes. Hemos trabajado desde el inicio para formar parte del proceso de crecimiento científico de nuestra profesión.

Desde entonces se han celebrado Congresos nacionales bianuales, se ha creado el Grupo de Docencia y de Investigación de SCELE, ya plenamente afianzado en sus actividades formativas en diferentes campos de la profesión, y se ha constituido la Revista electrónica Recien. Los tres grandes bloques de actividad están visibles en nuestra web http://www.scele.org/, que es un elemento de difusión, de visibilidad y de cohesión interna entre las áreas de actividad. 


\section{Los Congresos}

En 14 años se han realizado siete congresos nacionales, el último este mismo mes de mayo de 2014. Los lemas congresuales comenzaron reflexionando sobre nuestra profesión, su realidad y retos, sobre el espacio académico europeo, en definitiva sobre nosotras mismas.

Pronto decidimos hablar sobre lo que hacemos, investigamos, enseñamos o aprendemos cada día: los cuidados. Desde 2008 nos centramos en los cuidados de la cronicidad.

Esto significa una visión caleidoscópica que muestra distintas realidades:

- Modelos de cuidados encaminados a procurar el protagonismo, la autonomía y responsabilidad de la persona con cronicidad.

- Sistemas de continuidad entre niveles asistenciales que implican cuidados de calidad en el entorno próximo de las personas que lo precisan.

- La salud y su cuidado como derecho humano en el ámbito internacional y en los sectores sociales más frágiles.

- Sistemas de gestión de cuidados presenciales o de teleasistencia que ofrecen calidad, cercanía, continuidad, inmediatez y seguridad.

- Innovaciones docentes que forman nuevas enfermeras más críticas y capaces de intervenir con eficiencia y seguridad.

- Nuevas especialidades enfermeras, necesarias y esperadas.

- Todos estos temas han ido desgranándose en conferencias, mesas redondas y comunicaciones, forma viva y directa de pulsar qué pasa en los hospitales, los centros de salud, las universidades.

\section{Grupo de Docencia y de Investigación}

Además de los congresos, era necesaria una rama de actividad que orientara inquietudes formativas de educación para la salud, de investigación y de actualización en temas clínicos, legales u otros. Desde el Grupo de Docencia e Investigación (GDI) se canalizan las colaboraciones con otras sociedades científicas y grupos de investigación. 


\section{La revista Recien}

Mientras los congresos son esfuerzos conjuntos de SCELE para aglutinar los temas capitales y su debate, la revista Recien representa nuestra presencia investigadora en el mundo.

La revista apareció en 2010. Desde el inicio ha sido una gran caja de resonancia para SCELE, para sus congresos y comunicaciones y para la investigación en cuidados en general.

El no 5 de la revista recogió la actividad del VI congreso.

Ahora, el no 8 de Recien prácticamente es, un monográfico sobre el VII congreso de SCELE. Se presentan 33 comunicaciones de las que 26 son estudios de investigación concluidos o en ejecución y el resto son casos clínicos.

Si analizamos su lugar de origen, 12 de las 33 comunicaciones proceden de universidades: 3 de la U. Jaume I de Castellón y 9 de universidades catalanas, éstas últimas lo hacen en colaboración, bien con otras universidades tanto del estado español como extranjeras, bien con entidades asistenciales de Atención Primaria o de Atención Hospitalaria.

La Atención Primaria presenta 16 trabajos. De ellos, 10 de procedencia catalana, sobre todo de comarcas de Barcelona y Lleida, otras 5 comunicaciones proceden de las comarcas de Alicante y 1 de Castellón.

Las comunicaciones de Atención Hospitalaria son las menos numerosas: 3 del entorno de Alicante, 1 de Barcelona y 1 de Ciudad Real.

El contenido de todas las comunicaciones, a pesar de su enorme diversidad, parte de preguntas enfermeras que acrecientan nuestro conocimiento disciplinar.

Cuando se haga un estudio histórico de estos años, tal vez se pueda calibrar, con perspectiva, la importancia del trabajo sumatorio de todos y la contribución impulsora de SCELE.

Emilia Ramis Ortega Enfermera Máster Ciencias de la Enfermería. Hospital de San Juan de Alicante 